\title{
Reliability Analysis of Bearing System in High Speed Railway and Software Implementation
}

\author{
Yonghua $\mathrm{Li}^{\mathrm{a}}$, Pengpeng Zhib ${ }^{\mathrm{b}}$, Bingzhi Chen ${ }^{\mathrm{c}}$ and Yuedong Wang ${ }^{\mathrm{d}}$ \\ School of Traffic and Transportation Engineering, Dalian Jiaotong University, Dalian 116028, China \\ ayonghuali@163.com, bzhipengpeng2017@163.com, cchenbingzhi06@126.com, dwydstar@163.co \\ $\mathrm{m}$
}

Keywords: axle box bearing, system reliability, FMECA, FTA.

\begin{abstract}
In order to improve the reliability of high speed railway axle box bearing system, extend service life and reduce maintenance cost, the reliability analysis of high speed railway axle box bearing system was carried out based on the theory of system reliability design. Firstly, the reliability model of axle box bearing system was built and it was conducted with failure mode, effect and criticality analysis(FMECA) and fault tree analysis(FTA). Then, the reliability of the system was predicted and allocated. Finally, the reliability analysis software of high speed railway bearing was developed on the Visual Basic(VB) software. It has an important significance to find out the weak link of product design, maximize the bearing working potential, reduce the bearing fault and guarantee the security of the train.
\end{abstract}

\section{Introduction}

Axle box bearing is the key component in locomotive running gear of high speed passenger train. It has the function of bearing and transmitting load and guarantee the safety operation of the train[1]. At present, aiming at the research of high speed railway axle box bearing reliability, M.N. Kotzalas[2] and S.M. Zaharia[3] improved the reliability of the bearing by doing fatigue analysis of tapered roller bearing. X.F. Li[4] and P. Wang[5] used the fault diagnosis technology to give the correct judgment to the various failure symptoms of the axle box bearing, and extended the service life of the bearing. E.K. Koltsakis[6] set the contact stress model of bearing, improved the reliability of the bearing by the observation of the influence of the contact stress and the secondary surface stress on the bearing. All of the above studies were analyzed just on the bearings without considering the reliability of the axle box bearing system. This paper used the system reliability design theory to carry on the reliability analysis of axle box bearing system, and make the reliability analysis software of high speed railway bearing based on VB language. It has an important guidance for providing corresponding measures to reduce the incidence rate of bearing in the operation process, extending the service life and assuring the safe operation of trains.

\section{Reliability Analysis of High Speed Railway Bearing}

\subsection{The Establishment of the Basic Structure and Reliability Model of Axle Bearing System}

The bearing of the high speed train in China is using the double row tapered roller bearings now, the main components ares shown in Fig. 1.

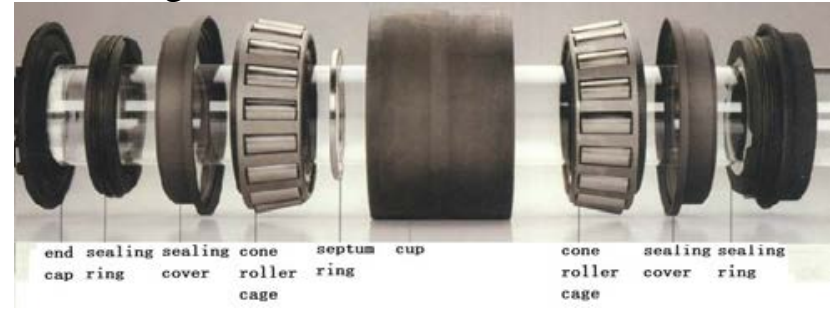

Fig. 1 Bearing structure of high speed railway

According to structure composition and working principle of the high speed railway bearing, the 
axle box bearing system satisfies the characteristics of the series system, its mathematical model can be expressed as

$$
R_{s}(t)=R_{1}(t) \times R_{2}(t) \times \cdots \times R_{n}(t)=\prod_{i=1}^{n} R_{i}(t)
$$

Where $\mathrm{Rs}(\mathrm{t})$ is the system reliability, $\mathrm{Ri}(\mathrm{t})$ is the reliability of the ith series parts.

The reliability block diagram of the box bearing system was obtained by equation (1), are offered in Fig. 2 below.

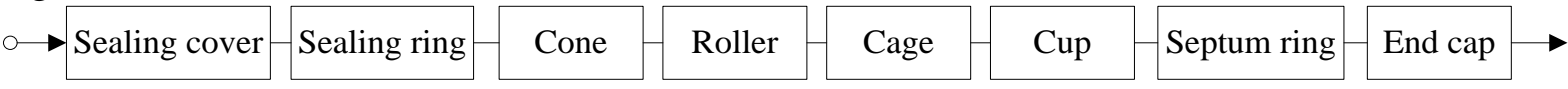

Fig. 2 Reliability block diagram of axle bearing system

\subsection{FMECA of Axle Bearing System}

FMECA of axle box bearing system is analyzing each potential failure mode of bearing products and ensuring their effects on the products[7]. According to the statistical data of the fault mode of the axle box bearing system, the FMECA calculated results has been put forward in Table 1.

Table 1 The FMECA results of the fault multiple parts

\begin{tabular}{|c|c|c|c|c|c|c|c|c|}
\hline Parts & Code & Failure Mode & Failure Causes & Failure Effects & $\lambda_{\mathrm{b}} / 10^{-3}$ & $\alpha_{\mathrm{j}}$ & $\beta_{\mathrm{j}}$ & $\mathrm{C}_{\mathrm{mj}} / 10^{-6}$ \\
\hline \multirow{4}{*}{ cone } & 01 & spalling & over load & surface spalling & 3.39 & 0.02 & 0.1 & 6.78 \\
\cline { 2 - 10 } & 13 & ware & impurity entry & cone ware & 3.35 & 0.15 & 0.05 & 25.4 \\
\cline { 2 - 10 } & 17 & fracture & over load & cone fracture & 3.39 & 0.01 & 1 & 33.9 \\
\cline { 2 - 9 } & 20 & corrosion & sealing failure & surface rust & 3.39 & 0.15 & 0.05 & 25.4 \\
\cline { 2 - 9 } & 22 & pitting & impurity entry & spalling & 3.39 & 0.15 & 0.5 & 254 \\
\hline cage & 07 & cage damage & vibrationa & cage deformation & 5.1 & 0.1 & 1 & 510 \\
\hline \multirow{5}{*}{ cup } & 01 & spalling & over load & surface spalling & 3.39 & 0.02 & 0.1 & 6.78 \\
\cline { 2 - 9 } & 13 & ware & impurity entry & cone ware & 3.35 & 0.15 & 0.05 & 25.4 \\
\cline { 2 - 9 } & 17 & fracture & over load & cone fracture & 3.39 & 0.01 & 1 & 33.9 \\
\cline { 2 - 9 } & 20 & corrosion & sealing failure & surface rust & 3.39 & 0.15 & 0.05 & 25.4 \\
\hline & 22 & pitting & impurity entry & spalling & 3.39 & 0.15 & 0.5 & 254 \\
\hline \multirow{4}{*}{ roller } & 01 & spalling & over load & surface spalling & 3.21 & 0.02 & 0.1 & 6.42 \\
\cline { 2 - 9 } & 13 & ware & impurity entry & cone ware & 3.35 & 0.15 & 0.05 & 25.4 \\
\cline { 2 - 9 } & 17 & fracture & over load & cone fracture & 3.39 & 0.01 & 1 & 33.9 \\
\cline { 2 - 9 } & 22 & corrosion & sealing failure & surface rust & 3.21 & 0.03 & 0.5 & 48.1 \\
\hline
\end{tabular}

\subsection{FTA of Axle Bearing System}

The paper regards bearing failure of bearing axle box system failure as the top event and regards cup fault, cone fault, roller fault and cage fault of multiple sites as an intermediate event preliminary. The fault trees of axle box bearing are shown in Fig. 3 and it is followed by the codes and names of basic events in Table 2.

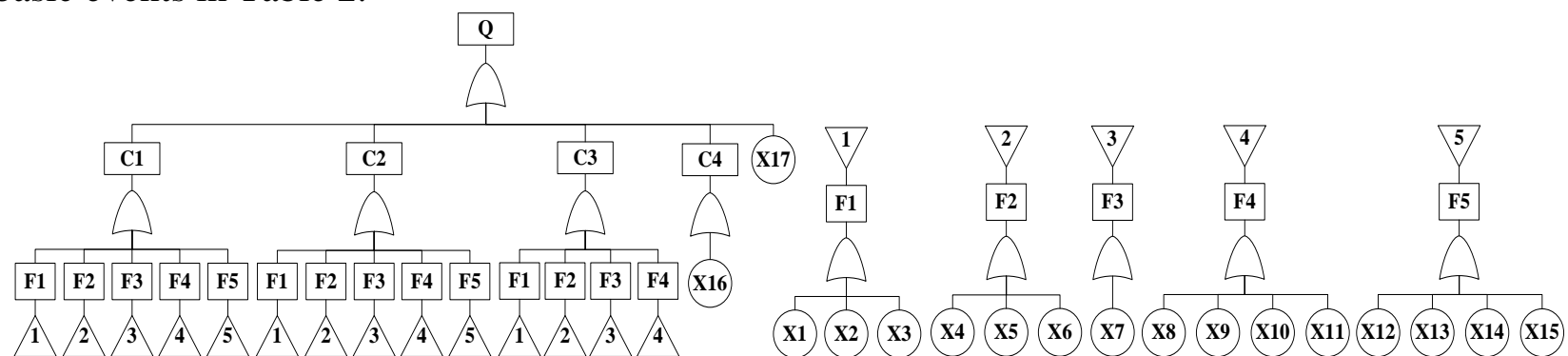

Fig. 3 The fault tree of axle box bearing 
Table 2 The codes and names of basic events

\begin{tabular}{|c|c|c|c|c|c|c|c|}
\hline Code & Event Name & Code & Event Name & Code & Event Name & Code & Event Name \\
\hline Q & Bearing invalid & F3 & Fracture & X5 & Low hardness & X12 & Impurity entry \\
\hline C1 & Cone invalid & F4 & Corrosion & X6 & Bad lubricant & X13 & Over load \\
\hline C2 & Cup invalid & F5 & Pitting & X7 & Over load & X14 & Bad lubricant \\
\hline C3 & Roller invalid & X1 & Over load & X8 & Bad lubrication & X15 & Friction \\
\hline C4 & Cage invalid & X2 & Bad installation & X9 & Sealing failure & X16 & Vibration \\
\hline F1 & Spalling & X3 & Bad lubrication & X10 & Bad prevention & X17 & Others invalid \\
\hline F2 & Ware & X4 & Impurity entry & X11 & Improper storage & & \\
\hline
\end{tabular}

\subsection{Reliability Prediction of Axle Bearing System}

Expert evaluation method was used for axle box bearing to predict the reliability. According to the document, the cage of axle box bearing was defined as the base part, the failure probability is 0.001 . Each part was estimated through this index, and the results of detailed reliability prediction are shown as Table 3.

Table 3 The results of reliability prediction

\begin{tabular}{|c|c|c|c|c|c|c|c|}
\hline Component & Complexity & $\begin{array}{c}\text { Operating } \\
\text { Hours }\end{array}$ & $\begin{array}{c}\text { Environmental } \\
\text { Condition }\end{array}$ & $\begin{array}{c}\text { Technical } \\
\text { Level }\end{array}$ & $\omega_{\mathrm{i}}$ & $\mathrm{C}_{\mathrm{i}}$ & $\lambda_{\mathrm{i}}$ \\
\hline cup & 5.2 & 5 & 6 & 6 & 936 & 0.29 & $2.93 \mathrm{E}-5$ \\
\hline cone & 4.2 & 5 & 5.4 & 5.8 & 657 & 0.74 & $1.67 \mathrm{E}-5$ \\
\hline roller & 4.4 & 5 & 5.2 & 5 & 572 & 0.64 & $6.45 \mathrm{E}-5$ \\
\hline cage & 5.6 & 4.4 & 6 & 6 & 887 & 1 & 0.001 \\
\hline sealing ring & 1.4 & 1.4 & 8.8 & 8.6 & 148 & 0.17 & $1.67 \mathrm{E}-5$ \\
\hline sealing cover & 1.4 & 2.4 & 9.2 & 8.4 & 300 & 0.29 & $2.93 \mathrm{E}-5$ \\
\hline septum ring & 1.4 & 1.8 & 8.4 & 9 & 191 & 0.21 & $2.15 \mathrm{E}-5$ \\
\hline end cap & 1.6 & 2.2 & 1.6 & 8.6 & 48 & 0.05 & $5.46 \mathrm{E}-6$ \\
\hline
\end{tabular}

\subsection{Reliability Allocation of Axle Bearing System}

Expert rating allocation method was used for axle box bearing to do reliability allocation. The reliability that the axle box bearing system runs for $1.2 \times 10^{-6} \mathrm{~km}$ without maintenance is $98.5 \%$ [1] and the reliability index is allocated among the components. It is shown as Table 4.

Table 4 The results of reliability allocation

\begin{tabular}{|c|c|c|c|c|c|c|c|}
\hline Components & Complexity & $\begin{array}{c}\text { Operating } \\
\text { Hours }\end{array}$ & $\begin{array}{c}\text { Environmental } \\
\text { Conditions }\end{array}$ & $\begin{array}{c}\text { Technical } \\
\text { Level }\end{array}$ & $\omega_{\mathrm{i}}$ & $\mathrm{C}_{\mathrm{i}}$ & $\lambda_{\mathrm{i}}$ \\
\hline cup & 6 & 5 & 6.5 & 5.8 & 1131 & 0.28 & $0.27 \mathrm{E}-3$ \\
\hline cone & 4.3 & 5 & 5.5 & 6 & 709 & 0.17 & $0.18 \mathrm{E}-3$ \\
\hline roller & 4.5 & 5.2 & 5.3 & 5.2 & 645 & 0.16 & $0.16 \mathrm{E}-3$ \\
\hline cage & 5 & 4.6 & 6 & 6.5 & 897 & 0.22 & $0.22 \mathrm{E}-3$ \\
\hline sealing ring & 1.6 & 1.4 & 8.5 & 8.8 & 167 & 0.04 & $4.13 \mathrm{E}-5$ \\
\hline sealing cover & 1.5 & 2.2 & 9.5 & 8.5 & 266 & 0.07 & $6.57 \mathrm{E}-5$ \\
\hline septum ring & 1.6 & 1.5 & 8.7 & 9.2 & 192 & 0.05 & $4.74 \mathrm{E}-5$ \\
\hline end cap & 1.5 & 2.5 & 1.5 & 8.5 & 48 & 0.02 & $1.18 \mathrm{E}-5$ \\
\hline
\end{tabular}

\section{Software Implementation}

The design goal of reliability analysis software of high speed railway bearing is based on the theory of system reliability. The function of software was realized on VB platform. The mainly modules are described in Fig. 4. 


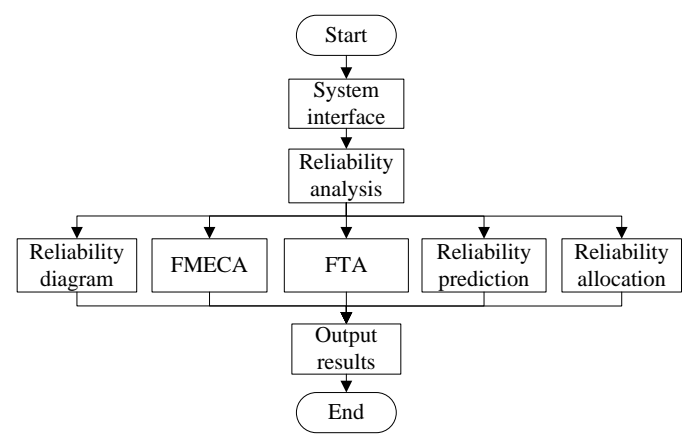

Fig. 4 Flow chart of software

Engineering database connected with VB is established based on Microsoft Access software. The software interface and the design of each module were finished by using VB language and the theory of system reliability design, are shown in Fig. 5.

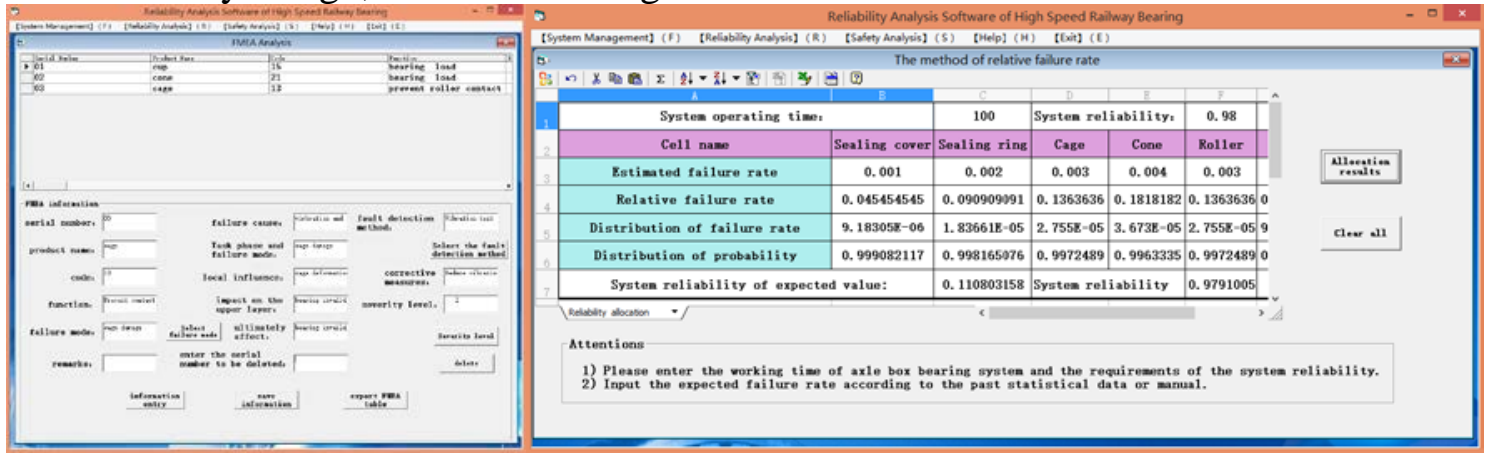

Fig. 5 Users operation interface

\section{Conclusions}

(1) In this paper, the reliability of high speed railway axle box bearing system was analyzed by using the system reliability design theory. It makes the system performance, manufacturing cost and life more coordinated compared with the reliability analysis of parts. The failure modes, effects, prediction and allocation were obtained by analysis. It plays an important role in designing the best axle box bearing system, ensuring the safety of high speed passenger train.

(2) The reliability analysis software of high speed railway bearing was developed combined the powerful programming function of VB with strong data processing, statistical analysis ability of the Access Microsoft database. The software provides a variety of functional modules of analysis for the reliability analysis of bearing system. The interface is concise and control organization is logical. The use of software operating which is close to the user habits of thinking can be convenient for users.

\section{Acknowledgments}

The authors would like to acknowledge the partial supports provided by the program of Educational Commission of Liaoning Province under contract number JDL2016001, the program of National Natural Science Foundation of Liaoning Province under contract number 2014028020, the program of the Dalian Science and Technology Project under contract number 2015A11GX026.

\section{References}

[1] X.W. Yang, Reliability for railway axle box bearings, Bearing. 10 (2013) 5-7.

[2] M.N. Kotzalas, Statistical distribution of tapered roller bearing fatigue lives at high levels of reliability, Journal of Tribology. 127 (2005) 865-870.

[3] S.M. Zaharia, Reliability and statistical analysis of the fatigue life of the tapered roller bearings, Scientific Research and Education in the Air Force-AFASES. 2 (2015) 1-6. 
[4] X.F. Li, L.M. Jia, X. Yang, Diagnosis of train axle box bearing based on multifeature parameters, Dynamics in Nature and Society. 2015 (2015) 1-8.

[5] P. Wang, P. Zhang, L.Y, Jing, et al, State inspection and fault diagnosis system of train axel box bearing based on virtual instrument, Key Engineering Materials. 693 (2016) 1436-1440.

[6] E.K. Koltsakis, P. Noury, M. Veljkovic, The contact problem of roller bearings: investigation of observed failures, Structural Engineering International. 26 (2016) 207-215.

[7] Y. Deng, Q. Li, Y. Lu, A research on subway physical vulnerability based on network theory and FMECA, Safety science. 80 (2015) 127-134. 